\title{
Les pobres Griseldes s'anaren empobrint amb els segles
}

\section{The poor Griseldes became impoverished over the centuries}

\author{
JÚLIA BUTINYÀ \\ juliabutinya@gmail.com
}

UNED

Resum: La figura literària de Griselda és mostra fefaent de la dona maltractada psicològicament. Des del conte de la literatura popular -font del Decameró-, tanmateix, ha anat canviant de status. A fi d'observar el recorregut als segles següents, cal partir de les versions medievals de Petrarca i de Boccaccio, lligades a la de Metge, ja que el relat es difon a través de les versions en llatí, italià i català. Per fer el seguiment temàtic en textos catalans, recorrem a documentació de caràcter popular o marginal, contrastant-la amb el curs dels relats griseldians, incloent alguns en castellà. De l'anàlisi desprenem que la defensa fermament humanística de la dona per part de Metge, manifesta al seu Griselda, s'interrompí arreu, fet que ens permetrà reflexionar sobre diverses qüestions de periodització literària.

Paraules clau: Griselda, Bernat Metge, Humanisme, segles XV-XVIII, perioditzacions

\begin{abstract}
Griselda's literary figure is a convincing example of a psychologically abused woman. Since the story of popular literature-source of the Decameron-, however, it has been changing its status. In order to observe the course in the following centuries, it is necessary to start from the medieval versions of Petrarch and Boccaccio, linked to that of Metge, as the story is spread through the Latin, Italian and Catalan versions. To deal with the thematic approach in Catalan texts, we resort to documentation of a popular or marginal nature, contrasting it with the course of Griseldian stories, including two famous Castilians. From the analysis we can see that the firmly humanistic defense of women by Metge, manifests in his Griselda, was interrupted everywhere, which will allow us to reflect on various issues of literary periodization.
\end{abstract}

Keywords: Griselda, Bernat Metge, Humanisme, XV-XVIII centuries, periodizations

\footnotetext{
* Cal agrair a l'equip organitzador -i en especial al professor Vicent J. Escartí- la realització del Congrés virtual internacional Proscrits, marginats i minories a la Corona d'Aragó (ss. XV-XVIII). Textos i vides, tan oportú en tan mals moments, i alhora felicitar-los per haver reeixit amb tan bon resultat, entenent que será de profit per l'avenç de les investigacions filològiques. I no sols de Filologia Catalana, ja que el Projecte Biografies marginals, on s'inscriu, abasta un ampli espectre, com bé palesen les cinc seccions que el conformen.

A tall de confirmació de la utilitat de la seva empenta, pel que fa a la meva participació, puc dir que hi tractava d'un punt petit, però que arran de la idea final relativa a les perioditzacions, se'm van obrir noves perspectives, que han quallat en dos treballs, que sortiran enguany a Mirabilia Med/Trans 12 i eHumanista/IVITRA 18. També, en conseqüència, aquesta versió escrita amplia alguns aspectes en dita direcció.
}

DATA PRESENTACIÓ: 04/11/2020 ACCEPTACIÓ: 10/11/2020 • PUBLICACIÓ: 10/12/2020 


\section{El primer pas, a la literatura italiana}

Cal partir del darrer conte del Decameró, que, amb la desgraciada Griselda al cim, com súmmum de virtut, corona la magna obra; és realçada entremig de les altres dones, en una obra orientada a elles i en què brillen els personatges femenins. La narració té un marc, la cornice, que és un dels components amb què Boccaccio establí la narrativa europea (Branca 2001: 29), així com Petrarca fixà la lírica. Ací, al relat X, 10, el precedeix la qualificació del comportament del marit com «matta bestialità), segons el personatge relator, Dioneo; qui ho remata al final, execrant-lo i dient amb humor negre que hi ha nobles que «sarien più degni di guardar porci» (Rossi 1991: 30, 62). Així doncs, el marc en dóna la clau de lectura deixant assentat que el marquès de Saluzzo, Valter, és un exemple antiexemplar d'extorsionador mental; avui, un típic cas de violència de gènere o de delinqüència per agressió psicològica. Vist, doncs, dins el seu context literari, el Griselda es converteix en una obra de denúncia, on, a més de l'admiració i compassió, que li són característiques pel to sentimental, ressalta l'acusació envers el marit, provocant la indignació.

El certaldès prengué el tema de la literatura popular, mantenint al Decameró que valorava la sana virtut del poble, la qual exalça, igual que fa en Genealogiae deorum amb els textos humils que provenen de llocs menyspreats, com poden ser les rondalles de les velles, en les nits d'hivern, al voltant del foc (XIV, $\mathrm{x})$, perquè tots poden ser portadors de veritats morals. Boccaccio, que anava contra la diglòssia lingüística, com mostrà fent una meravella amb la llengua vulgar, aplicava a la literatura el mateix principi antidiglòssic.

Ara bé, el conte agradà molt al seu amic Petrarca, qui, considerant-lo digne d'un major ennobliment, el traduí a un exquisit llatí (Griseldis); junt amb aquest ascens, amb el qual separava la noia de les altres decameronianes -algunes massa alliberades, diu-, vestia el relat amb una tirada religiosa; ho constata el colofó, on, segons la cita de l'epístola de sant Jaume (I, 13), l'home s'ha de portar amb Déu com Griselda amb Valter. D'aquesta manera, en comptes de criticar el marit, Petrarca el divinitzava; així també, el relat donava consistència al vell repartiment dels papers de la parella, valorant la paciència i submissió de la dona, martiritzada fins a l'extrem que li tragueren els fills per tal de provar la seva fidelitat amorosa. Sota aquests plantejaments, li enviava la traducció al certaldès, acompanyada de les seves darreres cartes - del llibre XVII de les Senils (Rossi 1991: 7480)-, a tall d'imprescindible marc. ${ }^{1}$

\section{Resposta des de la literatura catalana}

De la literatura catalana estant, poc després, Bernat Metge, afí al naturalisme de Boccaccio, torna el conte al romanç i el tradueix al català. Però ho fa sobre la traducció llatina, ja que això li permet manifestar per mitjà de petits retocs $i$ ironies les diferències ideològiques envers el gran mentor

1 La XVII, 3 començava amb un prefaci («Librum tuum») i cloïa amb un epíleg («Hanc historiam»); com que no arribà a destí -com tampoc ho havia fet la 2-, envià una $4^{\mathrm{a}}$, redactant altra carta inicial («Arsit amon»). 
dels humanistes i el seu gest d'ascensió. Metge, encara, continuant l'adhesió decameroniana cap a la dignificació de la llengua vulgar, fa de la seva versió en llengua catalana el primer text humanístic de la Península, com bé valorà Riquer (1964: 373-378; Metge 1959: *53-*58).

La diglòssia que atacava Metge es revela a les cartes adreçades a la destinatària (Ysabel de Guimerà), amb què, segons la lliçó dels mestres, embolcalla el seu Griselda. Metge aprofita l'avinentesa per defensar el caràcter real i per tant exemplar, que Petrarca -com que no era històrica, sinó ficció: una faula-, havia qüestionat a dites Senils; així doncs, Metge s'arrenglera amb Boccaccio, qui repetia al Decameró que els herois del poble ja ho eren de reals, així com els seus contes verídics, i on es planyia perquè el prenien per un contador de faules. El notari barceloní, que ha reprès l'esperit decameronià, accentuant el naturalisme literari i la càrrega moral (Marco 2013), contradiu encara el mentor traslladant el tema al pla ètic mitjançant una citació d'Ovidi, la qual considera el patiment com una oportunitat humana de creixement, en oposició a l'enfocament d'orientació religiosa de Petrarca. La discussió griseldiana Metge la mantindrà a Lo somni (Butinyà 2017), on l'atorga una gran volada, fins al punt que, dins la seva galeria de dones excelses, posa Griselda com únic exemple de virtut de dona cristiana i, cap al final, en congruència amb el Decameró, condemna els vicis dels homes, de manera fulminant, com havia fet Dioneo.

La Griselda catalana, doncs, és una àmplia i doble rèplica d'antimisoginisme i d'antidiglòssia. Metge ho remarca dient que Griselda és històrica -7 vegades en les poques línies de les cartes; fet que la justifica com modèlica front a l'argument petrarquesc desmereixedor d'exemplaritat-i ho repeteix un cop més -8 en total- en esmentar la seva propia versió al llibre IV de Lo somni. Referència aquesta que li torna a acostar a Boccaccio, per tal com la retrata dins l'humil escenari que hem vist de les Genealogiae, a través del qual Boccaccio rellevava la literatura baixa. La intertextualitat amb què anostra l'escena boccacciana és gairebé literal, dient que: «ja la reciten les velles per enganar les nits, en les vetles, com filen en ivern entorn del foch» (Metge 2007: 244); de manera que, així com tots dos autors afirmaven que no hi ha classes amb el gènere i la llengua, tampoc no n'hi ha amb els textos. ${ }^{2}$

\section{El recorregut del relat griseldià: del voltant del foc a voltar el món}

L'Humanisme, revolucionari i rupturista, es feia de coses així: petites rectificacions d'alt nivell, manifestades amb una perfecció exquisida i expressives de la dignitat humana, de l'home i de la dona. I Griselda, de l'àmbit recòndit del folklore, gràcies a la sublim ploma de Petrarca, passà ràpidament a best-seller i la veiem aviat de moda pertot Europa. Però l'expansió comportà un descuit i un

2 Aquests conceptes els he ampliat recentment en «Deu petiteses que magnifiquen la Griselda catalana», Mirabilia. Medtrans 12 (2020/2) i l'obra de Metge l'he traduïda al castellà en Projects. Publications of eHumanista, 2020. 


\section{Júlia Butinyà. Les pobres Griseldes s'anaren empobrint amb els segles}

empobriment, donat que el Griseldis, d'acord amb el seu marc, vehiculava una concepció tradicional de la dona (Hernández 1991: 399). Per tant, hi ha Griseldes en alemany, islandès, portuguès, rus, etc., despullades, però, de la profunda problemàtica plantejada.

La primera traducció fou la francesa, en què Philippe de Mézières no acusa cap sensibilitat envers la discussió inicial; com tampoc ho fa l'anglesa de Chaucer en Els contes de Canterbury. Encara medieval, la de Christine de Pisan té amb tot certa sensibilitat feminista, amb el benentès que és un manual d'educació en les virtuts pròpies de la dona, en què predomina la religiositat. Al segle XVII, Charles Perrault, autor de clàssics infantils, fa de Griselda un model d'esposes, com abans havia fet Mézières. En l'àmbit artístic destaquem algunes òperes al XVIII: la d'Alessandro Scarlatti amb llibret de Pietro Metastasio -el qual també havia musicat Albinoni- sobre el text decameronià, i la de Vivaldi, amb llibret de Carlo Goldoni, on Griselda, de marquesa, ha passat a reina.

\section{Contrast entre les tres grans Griseldes}

Tot plegat, podem desprendre que, després d'aquella dignificació de Boccaccio, amb dones reals i lliures, o la de Bernat Metge, que es perllonguen amb força i puresa en les dones esplèndides d'una novel la humanística com el Curial, res de res. I recordem com s'exalcen les dones a Lo somni, quan, havent desfilat les insignes heroïnes clàssiques davant de Griselda, Metge, en llur defensa, s'acara a l'endeví Tirèsias -interlocutor seu als dos darrers llibres- amb idees tan contundents com les que componen aquesta magnífica lloa:

Tu saps que, si dones no fossen stades, toda humana natura fore perida en Adam. No foren ciutats, castells ni cases; no foren reys, cavallers ne armes; no foren ciutadans, menestrals ne lauradors ne naus; no foren mercaders, ni mercaderies; no foren arts, leys, cànones ne statuts; ne foren festes, jochs, dançes ne amor, que totes coses sobrepuge.

Algú no sabera lo moviment dels cels e de les planetes, ne haguera conexença d'aquells; ne ençercara les operacions amagades de natura, ne sabera per què la mar infla ne en quina manera gita l'aygua per les venes de la terra, la qual puys torna cobrar; ne en quina forma són ligats los elaments entre ells, ne les influències dels corsos celestials; ne per què és la diversitat dels quatra temps de l'any, e de la granesa e poquesa dels dies e de les nits; ne per què respon Echo en les concavitats quant hom crida, ne per què lo levant tira los núvols pluyosos e la tremuntana los encalça; ne per què la terra tremola, ne moltes altres coses naturals que t'engendrarien fastig si les te dehia especificadament.

No ignores que, quant hom és sa o malalt, elles servexen pus diligentment e mils e pus netament que hòmens. Tart consellarien que hom vage en bregues, tavernes, jochs ne lochs deshonests. Si Èctor, Július Cèsar e Pompeu haguessen creegut consell de dones, lur vida no fore estada tant breu: les istòries clares són.

Ultra les malediccions que has recitat de dones en general, has dit terrible mal de la dona que jo més am en lo món. Dich-te que açò no poria pacientment tol lerar. Oges, donchs, e veuràs com te provaré lo contrari. (Metge: 2007, 254-257). 
La demostració darrera que s'anuncia ací-val a dir, els arguments contraris a l'atac misògin de Tirèsias a les dones que, mitjançant el Corbaccio, havia fet al llibre anterior, el III-, Bernat la pronuncia girantli tots aquells arguments; la resposta, descarada i en rodó, forma part del seu al legat aclaparador a favor de les dones. Ara bé, observem que l'estil hiperbòlic de la invectiva humorística concorda en gosadia amb aquesta lloa femenina que la precedeix, així com ambdós fets són seqüeles de la sublimació de la noieta com únic exemple de dona excelsa de la cristiandat. I donat que Metge és un moralista, la insistent exageració de les tintes convida a interpretar la virulència sota un carès de denúncia, el qual no és difícil d'assimilar al comentari paral lel de Dioneo en cloure el conte. Vista així, la irònica diatriba amb què Metge tanca el discurs moral dels dos darrers llibres de Lo somni és equivalent al judici amb què el relator del darrer conte del Decameró tancava el seu amb una sortida sarcàstica, tan dura com divertida, contra els homes. Visió de conjunt que és resultat d'haver llegit el relat sota l'aurèola de magnificació de Griselda, però dins del doble traç de l'original, que incloïa una reprovació interna i literària. El recurs formal de la cornisa també l'havia utilitzat Petrarca en emmarcar la seva traducció, però altrament, en forma d'epístoles alliçonadores per a l'autor.

Per consegüent, si s'havia contemplat el marc epistolar a madona Ysabel a la llum del petrarquesc, a Lo somni s'ha de veure el record redoblat per al lusions; car tots dos havien entès la funció de l'emmarcament als seus Griseldes, però Metge, al gran diàleg, recupera una part del primer marc, el boccaccià, que portava ben gravat; i, insatisfet amb la imitatio a l'estil del marc llatí, n'hi rescata tot el sentit crític primitiu. N'era un deute pendent. Aquesta lectura es recolza atenent que, com que Petrarca en el III llibre - disfressat de Tirèsias- recitava i aconsellava des del Secretum, Metge l'està contestant de nou al IV, com ja havia fet al Griselda; on així mateix eren els dos italians els seus col locutors i sobre la mateixa matèria. L'extrema precisió és una de les qualitats de Bernat Metge (Riquer 1964: 377).

Aquest aplec de detalls desfà la pregunta que fins no fa gaire es feia la crítica quant a poder constatar que conegués la versió decameroniana, però que Tavani ja subscriu (1996: 168), donat que evidencien que Metge no sols coneixia l'estil sinó que l'havia escorcollat (Ribera 2001: 564), així com estava molt familiaritzat amb altres obres de Boccaccio (com Il Comento, el Trattatello, De claris mulieribus, De casibus virorum illustrium; cfr. Metge 2007: notes 46, 159, 361, 487...). A qui prengué com mentor, mentre que tothom i arreu prenia Petrarca.

\section{Panorama del relat griseldià a la Península}

En llengua catalana, passant als segles que pertoquen a l'època del congrés -que, després del segle XV, entre l'etapa medieval i la Renaixença, podríem anomenar els segles «de l'Endemig»-, no he sabut trobar Griseldes de relleu. Dins els reculls folklorístics, però, es troba algun plec solt de canya i cordill als segles XVIII i XIX, com el Romanc extret de la novela, editat per A. Bulbena i Tosell, la Historia de Griselda, la qual «lo marqués Walter prengué por muller essent una humil pastorareta [sic], é isqué lo más singular exemple de la obediencia que tota dona casada deu tenir a son marit». 
Seguint el tema de la dona, recorro a un recull de textos invisibles literàriament que m'és proper, ${ }^{3}$ bé que he d'advertir que no en cal treure moltes cites, perquè hi basta una ullada per adonar-se del tractament consabut. Hi podem notar que en la comèdia de santa Quitèria, la més culturalista del recull, s'hi diu que la Carn, personatge que va de vermell, és «una senyora galán (...) que serà bona per sopar»; en continguts, de tota manera, s'hi pot rellevar una idea, però tòpica de l'època -que és la de Moratín-, car es critica el casament obligat (Butinyà / Prat / Vila 2000). La peça ostenta un lèxic injuriós molt ric, especialment subtil pel que fa a la dona (Butinyà 1998: 193-194). Al drama de sant Julià i santa Basilissa, que té algunes bromes picants i de mal gust, n'hi ha d'adreçades a les dones del públic i tot (Butinyà / Prat / Vila 2013). De l'autor d'aquesta darrera obra hagiogràfica, Narcís Collell, tenim també material d'estudiant, on les referències femenines reprodueixen la picaresca escolar: «anant a cercar ayga pels malalts, minyons de mals costums t'apedregaren y trencaren els cànters que portaves sota l'aixella» (Butinyà / Condom / Vila 1994). Heus ací la dona amb el paper estereotipat, anodí i objecte de burles; a tot estirar, si ostenta un caire positiu, porta un vano a la mà, aleshores tan de moda. Pobresa i vulgaritat com alternativa a ser absent.

Amb un salt en el temps, arribo a una Griselda dels voltants del Noucentisme -que no he pogut consultar-, il lustrada pel dibuixant Josep Obiols: Griselda, la campesina (amb un títol interior: Griselda, la campesina avispada 'cuento toscano') i publicada en castellà per l'editorial barcelonina Muntanyola (1916?); poc després, figurà com autor el valencià Juan Laguía.

A fi de seguir el contrast més àmpliament anirem a la literatura en castellà. Aquí, als segles XVI i XVII, Griselda és inspiració de dos autors: del valencià Joan de Timoneda, qui la insereix com la segona patraña del Patrañuelo -fonamentant-se al text metgià segons Romera (2009: 215)-, i de Lope de Vega, a la comèdia El ejemplo de casadas y prueba de la paciencia, de títol ben explícit (Butinyà: 2002a: 80-81). ${ }^{4}$ És una mostra petita però fefaent del moment daurat que al Renaixement vivien les lletres castellanes, que -com les catalanes als Segles d'or medievals- s'estaven al primer reng de l'actualitat. El seguiment d'edicions i traduccions en l'època renaixentista, que han desenvolupat Conde / Infantes (2000: 6779), permet comprovar que -a pesar d'estimar-se com joies- la davallada en riquesa de significacions front a l'Humanisme tingué lloc pertot arreu, segons acusen Griseldes d'autors molt notables.

\section{Reflexions sobre les perioditzacions}

Griselda, doncs, de la rica vivència dels primeríssims humanistes, ha passat als segles del congrés en un enllaç de tornada cap a l'Edat Mitjana, deixant un buit respecte a la discussió humanística i a les

3 El bagatge analitzat es troba a l'arxiu de can Butinyà, que conservo, procedent de l'aplec que salvà el meu avi, Martirià Butinyà, al segle XIX, comprant-lo als molins paperers i evitant així la seva destrucció. N'hi ha consuetes, quaderns d'estudi, llibretes de notaris i d'exercicis de llengua, peces de teatre, etc. (Butinyà 1996); estan publicades les obres de principal interès.

4 Entre aquestes pàgines a més poden veure un quadre amb les fonts de les cartes que envolten les Griseldes llatina i catalana, les quals s’hi estudien; fonts que són eloqüents del carácter de dits relats.

SCRIPTA, Revista internacional de literatura i cultura medieval i moderna, núm. 16 / desembre 2020 / pp. 267-278 ISSN: 2340-4841 ·doi:10.7203/SCRIPTA.16.19230 
greus i intricades problemàtiques que se'n derivaven; podríem dir que el seu pas ha estat de marxa enrere. Fet que fa reflexionar sobre les perioditzacions.

\subsection{Primera reflexió: dins d'una panoràmica general}

Un cop ultrapassat el moment del canvi propiciat pels grans trescentistes italians, ja al Renaixement, la projecció de les Griseldes s'identificà amb la de Petrarca, amb la consegüent perduració de la imatge de la dona tradicional -trepitjada als segles mitjos, si excloem l'amor cortès-; és a dir, va perviure amb bones vestidures literàries, però assegurant la vella tradició (Butinyà 2020a). Aquesta apreciació, la qual atesten les confrontacions efectuades, és útil per distingir entre Humanisme i Renaixement; distinció rellevant, car els moviments, com que no són estàtics ni rectilinis i vacil len entre continuïtat i discontinuïtat (Guillén 1985: 364-379), a vegades generen desorientació; a més, la inspiració als clàssics, element constitutiu de tots dos moviments, els pot fer confondre. Encara, la imatge triomfadora petrarquesca -amb el reverencialisme adherit- ha pogut contribuir a desdibuixar el primeríssim impacte humanista, on hem capbussat una mica.

Bé que algunes visions panoràmiques molt vàlides passen per alt aquest tipus de fluència, incloent els símptomes al tractament dels autors, si hom prescindís del concepte Humanisme, hi hauria el risc de desconcert. Així sembla que ha esdevingut a nivell internacional, car la manca de claredat o fins i tot la negació del moviment (Batllori 1995: 3-26) poden haver portat al guirigall actual quant a l'aplicació de les denominacions (humanista, prehumanista, humanista renaixentista, etc.); la desarticulació és sobretot flagrant davant el salt mortal que sobrevé quan, sense matisos, es transvasa de l'Edat Mitjana al Renaixement. Nogensmenys, tot i que el moviment es realitzi a cada cultura amb notes inherents i identificadores, malgrat les dissemblances i vicissituds, les literatures occidentals que, arran dels trescentistes italians, experimentaren la marca innovadora de l'Humanisme -encara que fos de manera confusa o tardana- acostumen a subscriure'l (Humanisme castellà, francès, polonès...), sota el criteri del factor renovador. Altrament, sense engranatges, l'evolució cultural es veu desconjuntada, enfosquint-se la seva comprensió. Perquè, amb cadència més o menys singular, el moviment eppur si muove i fa d'anella.

\subsection{Segona reflexió: de cara a la literatura catalana}

En aquest àmbit, la innovació que trencava amb vells estereotips mentals i que apuntava a una renovació de la moral i de la literatura en profunditat, va sorgir de manera molt intensa i pionera gràcies a Metge (Butinyà 2010), emulador de Petrarca; i hi és únic, com també és únic l'aretí a la literatura italiana. Amb tot, cal tenir present que, abans d'assimilar els italians al Griselda, ja en 1981, al Llibre de Fortuna e Prudència, havia començat l'allunyament del passat cultural, recolzant-se als llatins i a l’ombra de Lucà (Butiñá 2002b: 91-146). Seguiren la nova ànsia literària el molt italià 
Curial (Soler 2017) i un nucli efervescent amb configuració de mosaic a València. Tots tres casos, ben renovadors, que es donaren en un segle aproximadament i emprant la mateixa llengua -fora de l'afegitó de la llatina a redòs de la cort napolitana, la qual no treu alè humanístic, però-, responen amb coherència i naturalitat als llocs de predomini cultural sota les circumstàncies sociològiques de la Corona catalanoaragonesa: Barcelona, Nàpols i València (Butinyà 2002c). I és arriscat de perfilarhi exclusions sense un patró objectiu, comptant que no existeix una tarifa plana igualadora i que no hi han valgut intents proposats en altres ocasions, com la quantitat d'addictes. Als grans moviments -com passa amb el Romanticisme- els delaten les actituds per sobre d'aspectes com el pedigrí o la xifra d'integrants, la qual pot ser molt minoritària. L'audiència de Metge era la seva colla d'amics.

Ara bé, a través del tema de la dona, el qual és sensible a aquells canvis, hem confirmat el ralentí de l'empenta de renovació al període secular de l'Endemig. Comparativament quant al passat i en un pla cultural d'ampli abast, hi hagué una davallada, ja coneguda i que no caldria subratllar si no fos perquè l'oblit de la valoració de la propia aportació humanística anterior, tingué una ombra molt allargada ${ }^{5}$ i ben peculiar. Així, després dels esforços per subsanar dita pèrdua de ritme gràcies a un entusiasta renèixer decimonònic, al segle XX, pel que fa a la contribució sota el primer Humanisme, hom es troba amb màxims d'apreci -cap al principi-i de negació -cap al final-, perquè als darrers decennis s'arribà a ometre, fent controvertible àdhuc la seva existència. Costa de trobar motius de pes per diferir de les altres literatures davant l'espectacle de l'afany regenerador del classicisme del Curial (Gros 2015), de la dinàmica producció valenciana i de les originals i atrevides obres metgianes, trets de què aquelles molt sovint manquen, almenys amb aquesta intensitat; així s'entén que s'hagin inclòs amb normalitat al conjunt humanístic espanyol (González Rolán /Saquero / López Fonseca 2002).

A continuació, d'acord amb les reflexions generals, passo a extreure'n algunes conseqüències. Una és que les alteracions del nivell de qualitat, els esquemes preconcebuts, els sotracs, etc. sembla que no podrien fer desaparèixer les anelles d'un curs literari determinat i que, a l'igual que no és factible d'inventar-les, tampoc no es podrien anul lar, perquè -suaument o brusca- li donen joc. Això sí, amb que hi hagi vida; vitalitat de la qual n'és garantia el manteniment de la llengua, que ací fou sempre vivent fins en testimonis marginals com els que hem vist.

D'altra banda, una tradició ben estructurada en conserva reforçades les fites principals, valorant el seu caràcter i funció; d'una altra manera, es coneixen però no es comprenen. Així veiem obres ben representatives, com ara la Commedia o el Quixot, de les quals fins i tot la gent del carrer en sap parlar. Però si no passa així, potser és que no s'han comprès del tot, potser perquè no s'han inserit dins el context que les correspon amb tota la seva significació; això darrer s'ha verificat actualment amb el Curial, ja que, quan es llegia com medievalitzant, resultava una raresa. Els exemplars emblemàtics, com esdevé també amb Lo somni-totes dues obres de moments i entorns diferents però pertanyents

5 L'autor objecte de la meva tesi doctoral -F. Xavier Butinyà, SI, home de la Renaixença-, manifesta en cartes al seu amic, l'erudit Pere Alsius, l'admiració per la llengua catalana antiga, sent desconeixedor de les obres més significatives ací tractades. (Cfr. Solà / Marcet i Salom 1988: I: pp. 1060-1061, 1063; II: p. 1318).

SCRIPTA, Revista internacional de literatura i cultura medieval i moderna, núm. 16 / desembre 2020 / pp. 267-278 ISSN: 2340-4841 · doi:10.7203/SCRIPTA.16.19230 
a un mateix clímax cultural-, cal que estiguin contextualitzats dins de la seva anella. No és cap invent: Rubió i Balaguer ja estimulava a trobar les anelles de la tradició (1990: 142).

Així doncs, cal revalorar a fons la cruilla humanística i el seu espectre pel que té de baula o de frontissa, així com s'ha fet un esforç considerable ${ }^{6}$ cara a la recuperació d'aquells segles passats sense el bagatge cultural a l'abast. I aquesta revaloració ha d'atendre a obres que han pogut passar per menors o més subsidiàriament. Com la Griselda catalana, que és un monument literari, exponent d'una discussió per excel lència humanística i una de les tres grans Griseldes universals, bé que segueixi força desconeguda.

Com segona conseqüència -al meu discret entendre, perquè n'hi ha especialistes més especialitzats-, suggeriria de no excloure de l'etapa humanística el formidable conjunt del Quatre-cents valencià (Corella, March, Martorell, Villena...) pel fet que sigui barrejat quant a aparença i continguts; precisament, és una bona mostra del bull i l'amplada del moviment, que, des dels seus inicis, exhibí una gran diversitat, no sols ideològica -com hem vist- sinó també de formes, temes i gèneres. Ací, hi sura un segell comú, el de la voluntat de separació de la més vella mentalitat, sigui rebutjant les formes obsoletes, la cavalleria més medievalitzant, l’arcaica desestimació de la dona o inclús una rància religiositat.

Lligat a això es podria deduir una tercera conseqüència, perquè, si a aquell primer impuls a la Corona d'Aragó, molt pròxim als pioners italians, que conté una personalitat tan ferma com la de Metge, se li afegeix un autor que no procedeix del gran mar de l'Escolàstica (el del Curial) i hom li suma el pletòric conjunt de l'entorn valencià, sacsejat així mateix per les novetats, s'hauria de reconèixer com encertada la denominació tradicional d'Humanisme català (Butinyà 2003, 2008; Butinyà / Cortijo 2013).

I una vegada arribats ací, es fa imperiós remuntar als orígens, que en aquestes lletres ens condueixen indefectiblement a una figura de ressò internacional: el mallorquí Ramon Llull; no ja a causa de la llengua, ans pel seu signe d'identitat. ${ }^{7} \mathrm{Ja}$ ho advertí Rubió i Lluch en reconèixer-lo intuïtivament i sagaç al darrere de Bernat Metge, el pensament del qual qualificà de «palesa derivació luliana» (Rubió i Lluch 1918: 75). Autors que constitueixen la denominació d'origen d'aquesta cultura i que, amb autèntica devoció filològica, cal mantenir ben col locats al seu lloc.

Tanmateix, hom podria dir que, al capdavall, tot depèn de la definició d'aquest segon Humanisme -que desvetllava el primer, el clàssic-; però no hi errarem massa si la posicionem prop de l'origen, tot just al moment i caliu que hem atès, d'on -gràcies a Griselda- no es pot extirpar cap dels dos italians ni, en bona lògica, el català.

6 Cal fer referència als investigadors de mitjans del segle XX -entre els quals, Antoni Comas-i també als més recents, procedents sobretot del país Valencià -entre els quals, Vicent J. Escartí.

7 Per la vertebració de la literatura catalana medieval des de Llull, sota un punt de vista global, cfr. Butinyà 2020c, i des del formal ací tractat -en concret, pels marcs-, id. 2009: 249-251. 


\section{Bibliografia}

Anònim (2013) «La comèdia de sant Julià i santa Basilissa», eHumanista /IVITRA 3, Butinyà, J. / Prat, E. / Vila, P. (eds.), pp. 398-542. https://www.ehumanista.ucsb.edu/sites/secure.lsit.ucsb. edu.span.d7_eh/files/sitefiles/ivitra/volume3/17_butinya.pdf

Anònim (2000) «La comèdia hagiogràfica de santa Quitèria. Edició del text», Butinyà, J. / Prat, E. / Vila, P. (eds.), Annals de l'Institut d'Estudis Gironins 41, pp. 191-266. http://www.raco.cat/index. $\mathrm{php} /$ AnnalsGironins/article/view/54370

Badia, L. (1996) «El terme 'Humanisme' no defineix la cultura literària dels nostres escriptors en vulgar dels segles XIV i XV», L'Avenç 200, pp. 20-23.

Batllori, M. (1995) Obra completa V, De l'Humanisme i del Renaixement, València, Tres i Quatre, 1995.

Branca, V. (2001) «Boccaccio protagonista nell’Europa letteraria fra tardo Medievo e Rinascimento», dins

Hernández Esteban, M. (ed.), La recepción de Boccaccio en España. Cuadernos de Filología Italiana. Actas del Seminario Internacional Complutense 18-20 de octubre de 2000 (2001/3), Madrid, Universidad Complutense, pp. 21-37.

Butinyà, J. (2020a) «Deu petiteses que magnifiquen la Griselda catalana, Mirabilia / Medtrans 12, en curs de publicació.

—. (2020b) El Griselda de Bernat Metge en español, dins Projects. Publications of eHumanista, en curs de publicació.

- (2020c). «Dels primeríssims humanistes a Llull, passant per Dante, eHumanista/IVITRA 18, en curs de publicació.

- (2017) «Del Griselda a Lo somni», dins Simposi: Transmisión del patrimonio cultural. Clásicos traducidos que hacen clásicos (Transmisión, traducción, recepción), eHumanista/IVITRA 12, pp. 211-221. http://www.ehumanista.ucsb.edu/sites/secure.lsit.ucsb.edu.span.d7_eh/files/sitefiles/ivitra/ volume12/C/3.1.\%20Buti\%C3\%B1\%C3\%A1.pdf

- (2010) «Bernat Metge», dins Panorama Crític de la Literatura Catalana. I. Edat Mitjana, Hauf, A. (ed.), Barcelona, Vicens Vives, pp. 311-353.

- (2009) «El marc del Libre de contemplació i Boccaccio, Revista de Lenguas y Literaturas Catalana, Gallega y Vasca 14, pp. 233-252. http:// revistas.uned.es/index.php/RLLCGV/article/view/5953

- - (2008) «El Humanismo catalán en el contexto hispánico», dins El Humanismo hispano, Prendes, S. M. (ed.), «La Corónica. A Journal of Medieval Hispanic, Languages, Literatures \& Cultures» 37/1, pp. $27-71$.

. (2003 [2004]) «Sobre el Humanismo catalán y las periodizaciones», dins Del Humanismo, Revista de Lenguas y Literaturas Catalana, Gallega y Vasca 9, pp. 251-278. http://revistas.uned.es/ index.php/RLLCGV/article/view/5867/5594 
Butinyà, J. (2002a) Del Griselda català al castellà, «Minor» 7, Barcelona, Reial Acadèmia de Bones Lletres de Barcelona http://www.boneslletres.cat/publicacions/Altres_publicacions/b29314331.pdf

. (2002b) En los origenes del Humanismo: Bernat Metge, Madrid, UNED.

(2002c) «Barcelona, Nápoles y Valencia: tres momentos del Humanismo en la Corona de Aragón», dins Historia y poética de la ciudad. Revista de Filología Románica, pp. 91-107. http:/ / dialnet. unirioja.es/ejemplar/59045

—. (1998) «Una comèdia de santa Quitèria del segle XVII», Annals de l'Institut d'Estudis Gironins 39, pp. 175-198. https://www.raco.cat/index.php/AnnalsGironins/article/view/54304/63670

— - (1996) «El teatro tradicional catalán de los siglos XVII al XIX», Revista de Lenguas y Literaturas Catalana, Gallega y Vasca 4, pp. 59-83. http://revistas.uned.es/index.php/RLLCGV/article/ view $/ 5709 / 5436$

Butinyà, J. / Condom, D. / Vila, P. (1994) «El quadern d'exercicis catalano-llatins de Narcís Collell (1740-1744)», Quaderns del Centre d'Estudis Comarcals de Banyoles, pp. 229-241.

Butinyà, J. / Cortijo, A., coords. (2013) Catalan Humanism. eHumanista 13. https:/ /www.ehumanista. ucsb.edu/volumes/13

Conde, J. C. / Infantes, V. (2000) La Historia de Griseldis (c. 1544), «agua y peña» 12, Viareggio-Lucca, Mauro Baroni.

González Rolán, T. / Saquero, P. / López Fonseca, A. (2002) La tradición clásica en España (siglos XIIlXV). Bases conceptuales y bibliográficas, Madrid, Clásicas.

Gros, S. (2015) «Aquella dolor amarga». La tradició amatòria clàssica en el 'Curial e Güelfa', València, Publicacions de la Universitat de València.

Guillén, J. (1985) Entre lo uno y lo diverso. Introducción a la Literatura Comparada, Madrid, Crítica.

Hernández Esteban, M. (1991) «Lecturas del relato de Griselda: Decameron X, 10 y Seniles, XVII, 3,» Rivista di Letteratura Italiana 9/3, pp. 373-399.

Marco Artigas, M. (2013) «Les cartes-marc de la història de Valter e Griselda de Bernat Metge i les del Griseldis de Petrarca», Scripta. Revista de literatura i cultura medieval i moderna 2, pp. 270-282. https:/ / ojs.uv.es/index.php/scripta/article/view/3094/2673

Metge, B. (2010) Libre de Fortuna e Prudència, Marco, M. (ed.), Barcelona, Reial Acadèmia de Bones Lletres de Barcelona / IVITRA, 2010.

—_. (2007) Lo somni. El sueño, Butinyà, J. (ed. i trad.), Madrid, Palas Atenea.

—. (1959) Obras de Bernat Metge, Riquer, M. de (ed. i trad.), Barcelona, Universidad de Barcelona.

Ribera, J. (2001) Narradores y receptores boccaccianos en el medievo catalán, dins Hernández Esteban, M. (ed.), La recepción de Boccaccio en España. Cuadernos de Filología Italiana. Actas del Seminario Internacional Complutense 18-20 de octubre de 2000 (2001/3), Madrid, Universidad Complutense, pp. 559-571. 
Riquer, M. de (1964) Història de la Literatura Catalana 2, Barcelona, Ariel.

Romera, J. (2009) «Bernat Metge y Joan Timoneda (patraña segunda): El doble filo de la imitatio», eHumanista 13, pp. 210-218. https://www.ehumanista.ucsb.edu/volumes/13

Rossi, L. C. La novella di Griselda fra Boccaccio e Petrarca, «La memoria» 229, Palermo, Sellerio, 1991.

Rubió i Balaguer, J. (1990) Obres de Jordi Rubió i Balaguer 8, Barcelona, Publicacions de l'Abadia de Montserrat.

Rubió i Lluch, A. «Joan I humanista i el primer període de l'humanisme català», Estudis Universitaris Catalans X (1917-18): 1-117.

Solà, J. / Marcet i Salom, P. (1998) Història de la lingüística catalana 1775-1900. Repertori crític, Barcelona, Eumo, 2 vol.

Soler, A. (2017) La cort napolitana d'Alfons el Magnànim: el context de "Curial e Güelfa», València / Barcelona, Universitat de València / Institució Alfons el Magnànim / Institut d'Estudis Catalans, 3 vol.

Tavani, G. (1996) Per a una història de la cultura catalana medieval, Barcelona, Curial. 